\title{
2020 Recipients of Foundation Research and Education Grants and ASHP PLA Scholarship
}

\section{CONGRATULATIONS TO THE 2020 RECIPIENT OF THE FOUNDATION RESEARCH GRANT}

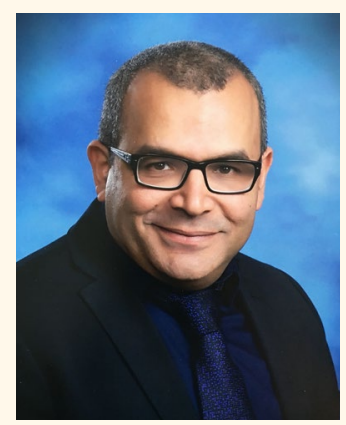

\section{Sherif Mahmoud}

Clinical Associate Professor, Faculty of Pharmacy and Pharmaceutical Sciences, University of Alberta

Nimodipine Pharmacokinetic Variability and its Impact on Outcomes in Patients with Aneurysmal Subarachnoid Hemorrhage: A Prospective Observational Study

Research Grant: $\$ 10,000$

Facility: University of Alberta, Edmonton, Alberta

\section{CONGRATULATIONS TO THE 2020 RECIPIENTS OF THE FOUNDATION EDUCATION GRANTS}

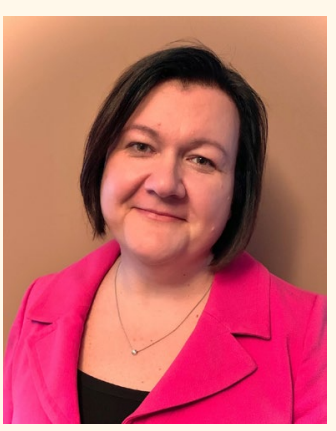

\section{Susan Cubelic}

Director of Pharmacy, Niagara Health System

Development of a Scientific TRanslation Accelerator Program (STRAP) for

Case Report Publication

Education Grant: $\$ 4,654$

Facility: Niagara Health System, St. Catharines, Ontario

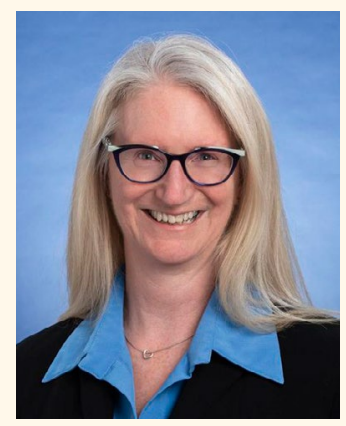

\section{Linda Dresser}

Assistant Professor, Leslie Dan Faculty of Pharmacy, University of Toronto

The Toronto-Area Antimicrobial Dose Adjustment (TAADA) Working Group: Regional

Consensus Guidelines and Implementation

Education Grant: $\$ 5,000$

Facility: Leslie Dan Faculty of Pharmacy, University of Toronto, Toronto, Ontario

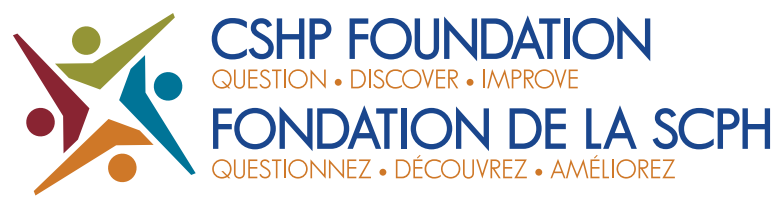




\section{CONGRATULATIONS TO THE 2020 RECIPIENT OF THE ASHP FOUNDATION PHARMACY LEADERSHIP ACADEMY SCHOLARSHIP}

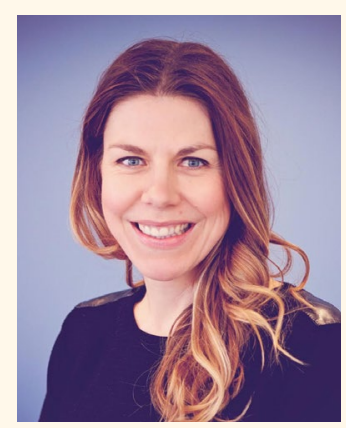

\section{Deonne Dersch-Mills}

Clinical Practice Leader, Pharmacy Services Research Coordinator, Alberta Health Services, Calgary, Alberta

Scholarship: $\$ 9,428$

American Society of Health-System Pharmacists (ASHP) Foundation Pharmacy Leadership

Academy Scholarship

If every member of the

Canadian Society of Hospital Pharmacists (CSHP)

were to donate $\$ 25$ in 2021, the Foundation would have

over $\$ 85,000$ to fund future grants and scholarships.

\section{Donate now}

Not a CSHP member?

Become one now and help shape the future of hospital pharmacy.

\section{Join today}

Visit us at: cshp.ca/cshp-foundation

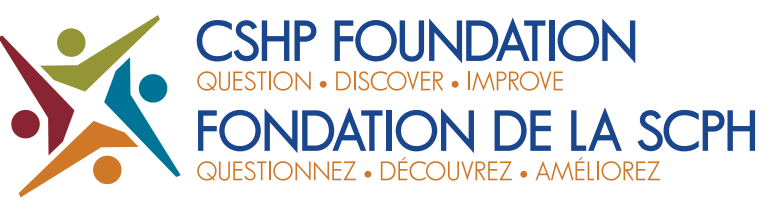

